\title{
Socioeconomic inequalities in health in older women
}

\author{
Berit Rostad · Dorly J. H. Deeg · Berit Schei
}

Published online: 4 December 2008

(C) Springer-Verlag 2008

\begin{abstract}
Socioeconomic status differentials in health are well documented. Less is known about the socioeconomic variation in health in older people, and in older women in particular. The aim of the study was to examine the association between socioeconomic status and health in older women in relation to two indicators of socioeconomic status and three measures of health, and further, to investigate whether socioeconomic differences in health increase or decrease with advancing age. Data from a cross-sectional population based health survey inviting all women $\geq 70$ years were analysed; 6,380 women aged 70103 years participated. Logistic regression was applied to analyse variation in health by socioeconomic status. Disadvantaged socioeconomic status (i.e. lower educational levels and previous manual or never been in paid work) was significantly associated with poorer health outcomes, whether measured as self-assessed health or depression. Limiting long-standing illness was significantly associated with never been in paid work. The associations were not attenuated by simultaneous adjustments for health behavioural factors, social support, and marital status. Additional adjustments for medical conditions did only alter the significant association between employment status and limiting long-standing illness. The analyses revealed that educational inequalities did not decrease with advancing age, whereas the results for employment varied across age
\end{abstract}

B. Rostad $(\bowtie) \cdot$ B. Schei

Department of Public Health and General Practice, Faculty of Medicine, MTFS, Norwegian University of Science and Technology, NTNU, 7489 Trondheim, Norway

e-mail: berit.rostad@ntnu.no

D. J. H. Deeg

VU University Medical Centre, LASA, Amsterdam,

The Netherlands groups. Our findings suggest an enduring relation between socioeconomic status and health in later life. The study adds to the understanding of the consistent associations between poorer health and social disadvantages at older age. We are not aware of any previous study showing the persistence of social inequalities in health upon adjustments for medical conditions.

Keywords Socioeconomic factors - Morbidity · Old age $\cdot$ Women

\section{Introduction}

Studies on socioeconomic inequalities in health in women have largely concerned women in the working age population. Less research attention has been paid to older women on account of the "assumptions of homogeneity in the older population" (Grundy and Holt 2001, p. 895). Studies on health inequalities in older women are sparse, and the results are inconsistent (Arber and Ginn 1993). In some studies, there is evidence that disadvantaged social conditions such as low educational and occupational position earlier in life are associated with poorer health in later life (Grundy and Holt 2001; Huisman et al. 2003), while other studies have found that these factors are not consistently associated with health (Berkman and Gurland 1998; Avlund et al. 2003; Broese van Groenou et al. 2003; von dem Knesebeck et al. 2003). The research indicating persisting socioeconomic differentials in health in women into older ages argues whether they decline with advancing age due to less diverse social situation and to greater equalisation of health risks (Arber and Ginn 1993; Huisman et al. 2003) or if the health advantages of higher socioeconomic status (SES) will accumulate through life 
and increase socioeconomic differences late in life (Ross and Wu 1996).

Theories about the relation between SES and health emphasises that health behavioural and psychosocial factors may partly explain health differentials (Bartley 2004). In general, people in unfavourable SES have less beneficial health behaviours and less psychosocial resources (Berkman and Glass 2000; Bartley 2004).

Women's health is related to their position in the family, and in general married women enjoy better health than those not (Arber 1991; Joung et al. 1994; Waldron et al. 1996). Few studies have included older women in analysing the impact of marital status on health, and the results are inconclusive (Goldman et al. 1995; Grundy and Holt 2000). An ongoing discussion is whether the effect of marital status on health varies over the life span. It is plausible that the beneficial effects of marriage such as increased income and emotional support, reduced unhealthy behaviour and stress, are less important in older women, who may be in a stressful position providing care to a spouse in frail health (Waldron et al. 1996). Marital status is strongly related also to women's employment patterns, though the association between marital status, occupation and health is not entirely clear (Arber 1990).

Health deteriorates with age: later life is a time of universal ill-health, which may obscure socioeconomic differences in health apparent at earlier ages. Inequalities in health may thus be age-dependent. If women in lower socioeconomic positions have both poorer health and shorter life expectancy than women more favourably placed, then the former surviving into older ages will be more highly selected than the latter. The selection effect might accumulate with advancing age. These mechanisms might diminish differences in social position. Further, pathology may affect health assessments; thus, the presence of medical conditions may govern health evaluations.

Good health is of pivotal importance to the lives of older women to remain independent and autonomous. It is remarkable that socioeconomic factors associated with good health are less studied in older women with the greatest ill-health and highest use of health resources (Arber and Ginn 1993).

Studies on SES differences in older women have rarely been population-based. The sample sizes have been restricted, the age spans narrow, and the applied socioeconomic and health indicators limited. We were in a fortunate position having comprehensive data of an unselected population of women constituting a good sample size, enabling us to look at explanatory factors that might link SES and health. There were no age restrictions for $\geq 70$ years of age; thus, we could examine social inequalities among the oldest old. Socioeconomic factors might differentially affect different dimensions of health. Our analyses included three health indicators: self-assessed health, depression and limiting long-standing illness. In this study, we aimed at examining the associations between SES and health controlling for health behaviour and psychosocial factors, and marital status. A further aim was to assess any influence of medical conditions on health evaluations. The estimated associations in the SES and health relationship were explored in relation to age, to determine whether socioeconomic disparities in health diminished or increased with advancing age.

\section{Methods}

\section{Study population}

The current study is based on a cross-sectional population-based health survey conducted from 1995 to 1997 (inviting all men and women $\geq 20$ years) in a Norwegian county (the Nord-Trøndelag Health Study, HUNT). All invited women aged 70 years and above living in the county (9,206 women) were eligible for the present study, and 6,760 women participated (participation rate $73.4 \%$ ). Available data were obtained for 6,380 women, making the participation rate for the present study $69.3 \%$ of all women invited (thus a total of 2,826 women were not analysed in the present study). The 6,380 women aged 70-103 years completed comprehensive selfadministered questionnaires on socioeconomic and health factors. Data were complemented by information on education and previous employment status (unavailable in HUNT 1996-1997) from a previous health survey (HUNT 1984-1986).

\section{Socioeconomic and demographic variables}

Social determinants of health were derived from reports of the participants' level of completed education and previous employment. Education had eight categories, but most women $(69 \%)$ had left school at compulsory level (7 years), thus limiting the extent of differentiation. To avoid very small numbers in each category, years of schooling was summarised into three categories: $\geq 12$ years, 8-11 years and $\leq 7$ years. Employment measures determined from the women's previous position in the labour market were classified into three categories: nonmanual (previously holding academic-, superior management and managerial positions), and manual work (previously in semiskilled and unskilled manual work and farmers), and a never in paid work category consisting of those reporting never having been in paid work or having been full-time housewives. Age was split into 5-year bands, with $\geq 85$ years as the oldest age group. Marital status was 
classified using three categories, married, previously married [divorcees (4\%) and widows] and never-married.

\section{Health measures}

Comprehensive health measures were applied: self-assessed health, limiting long-standing illness, and depression. Self-assessed health was based on a four-point scale from very good, good, not so good and bad, dichotomised into good and poor self-assessed health. The presence or absence of functional disability was assessed by reported information (yes or no) on any long-standing illness limiting daily life activities. The third health indicator was depression based on the Hospital Anxiety and Depression Rating Scale (HADS) using the seven questions for depression (HADS-D) (Zigmond and Snaith 1983). The ranges of scores were $0-21$. Depression was defined as HADS-D score of 8 or higher (Bjelland et al. 2002). For medical conditions, we selected three both common and severe conditions. Respondents were asked to tick off affirmative or negative replies to ever suffered from cardiovascular conditions (infarction, angina, stroke), cancer, and to confirm whether their doctor have said they had any musculoskeletal condition, replies were collapsed into having or not having the mentioned medical conditions.

Two indicators measured health-related behaviours. Alcohol consumption was registered according to replies on monthly frequency of consumption and alcohol units and affirming to "I am an alcohol-abstainer". The variable was dichotomised into abstainers and nonabstainers (there were insufficient numbers to allow robust analysis of less broadly defined items, as most women were drinking twice or less per month and 95\% consumed less than two alcohol units monthly). Smoking habits were registered as nonsmokers (including 854 previous smokers, mean years since cessation of smoking: 18 years) and current smokers.

The available psychosocial factor social support was defined by self-perceived adequacy of social support derived from responses (yes or no) to the question on having enough friends or relatives (excluding family members and persons with whom the woman was coresident) as confidantes, and whom they could count on for providing emotional and instrumental support when needed.

\section{Statistical analysis}

Statistical analyses were undertaken using SPSS for windows, version 14.0. Descriptive results are presented in total and relative numbers, and estimated $P$ values. Logistic regression was employed to compare socioeconomic factors with the selected health variables. Odds ratios (ORs) were used to assess the significance of differences in distributions on the health measures by socioeconomic factors, and 95\% confidence intervals (CIs) were estimated. All variables were coded as categorical with the most advantaged group taken as the reference category for each predictor variable. For the age-stratified analyses, two measured were calculated. First, rate differences express the absolute difference of the prevalence of health indicators between two groups of contrasting SES, by subtracting prevalence rates in highest SES from lowest SES. Second, ORs, indicating the ratio of the odds of having a health problem in the lowest educational and employment category compared to the highest educational and employment position, were derived from logistic regression analysis.

\section{Results}

Characteristics of the women by age are presented in Table 1 . Women in the lowest and highest age groups were relatively better educated. The proportion of women with higher level of education was comparable with that of elderly women in other European countries in mid-1990s (Huisman et al. 2003). There was a marked fall in employment rate with age, and significant differences in proportions in nonmanual opposed to manual occupation were observed. The never-married women were relatively better educated and more often in nonmanual work, while the married women had more often been employed (data not shown). The age gradient in health was somewhat inconsistent (Table 1). Subanalyses showed that women in a previous privileged employment position reported significantly less often musculoskeletal and cardiovascular conditions, as did the best educated regarding cardiovascular condition, while cancer was unrelated to social position (data not shown). Subanalyses showed that there was an apparent social patterning of unhealthy behaviour, the better educated and the previously nonmanually employed being less likely to be alcohol abstainers and nonsmokers. Lack of social support was not significantly related to education or employment status (data not shown).

Table 2 shows the differentials in health evaluations associated with socioeconomic factors. Socioeconomic inequalities in all three health variables were found; women in a disadvantageous socioeconomic position, such as lower levels of education and previously holding a manual occupation or never been in paid work, did significantly more often evaluate their health unfavourably, with the exception of limiting long-standing illness where the associations were somewhat inconsistently significant. Adjustments for age and various factors did, with few exceptions (inconsistent associations for limiting longstanding illness), not alter the significant associations. 
Table 1 Characteristics of older women by age

\begin{tabular}{|c|c|c|c|c|c|}
\hline Characteristics $^{\mathrm{a}}$ & $\begin{array}{l}\text { Age } 70-74 \\
N=2,382(37 \%)\end{array}$ & $\begin{array}{l}\text { Age } 75-79 \\
N=2,064(33 \%)\end{array}$ & $\begin{array}{l}\text { Age } 80-84 \\
N=1,231(19 \%)\end{array}$ & $\begin{array}{l}\text { Age } \geq 85 \\
N=703(11 \%)\end{array}$ & $\begin{array}{l}\text { Total } \\
N=6,380(\%)\end{array}$ \\
\hline \multicolumn{6}{|l|}{ Socioeconomic factors } \\
\hline \multicolumn{6}{|l|}{ Education* } \\
\hline$>12$ years & $108(5)$ & $70(4)$ & $28(3)$ & $27(5)$ & $233(4)$ \\
\hline $8-11$ years & $591(30)$ & $451(26)$ & $238(23)$ & $164(28)$ & $1,444(27)$ \\
\hline$\leq 7$ years & $1,291(65)$ & $1,191(70)$ & $772(74)$ & $382(67)$ & $3,636(69)$ \\
\hline \multicolumn{6}{|l|}{ Previous employment* } \\
\hline Nonmanual & $552(29)$ & $354(19)$ & $157(14)$ & $77(12)$ & $1,140(21)$ \\
\hline Manual & $551(28)$ & $432(24)$ & $223(19)$ & $88(13)$ & $1,294(23)$ \\
\hline Never in paid work & $843(43)$ & $1,031(57)$ & $769(67)$ & $501(75)$ & $3,133(56)$ \\
\hline \multicolumn{6}{|c|}{ Sociodemographic factors } \\
\hline \multicolumn{6}{|l|}{ Marital status* } \\
\hline Married & $1,299(54)$ & $828(40)$ & $310(25)$ & $76(11)$ & $2,504(39)$ \\
\hline Previously married & $963(41)$ & $1,108(54)$ & $812(66)$ & $547(78)$ & $3,430(54)$ \\
\hline Never-married & $129(5)$ & $128(6)$ & $109(9)$ & $80(11)$ & $446(7)$ \\
\hline \multicolumn{6}{|l|}{ Health indicators } \\
\hline \multicolumn{6}{|l|}{ Self-assessed health* } \\
\hline Good & $1,239(53)$ & $918(46)$ & $477(41)$ & $236(43)$ & $2,870(47)$ \\
\hline Poor & $1,112(47)$ & $1,084(54)$ & $681(59)$ & $313(57)$ & $3,190(53)$ \\
\hline \multicolumn{6}{|l|}{ Long-standing illness* } \\
\hline No & $1,186(66)$ & $862(59)$ & 418 (49) & $199(48)$ & $2,668(59)$ \\
\hline Yes & $616(34)$ & $595(41)$ & $426(51)$ & $212(52)$ & $1,849(41)$ \\
\hline \multicolumn{6}{|c|}{ Depression $H A D S \geq 8^{* *}$} \\
\hline No & $1,525(83)$ & $1,164(82)$ & $625(80)$ & $308(83)$ & $3,622(82)$ \\
\hline Yes & $304(17)$ & $255(18)$ & $157(20)$ & $64(17)$ & $780(18)$ \\
\hline \multicolumn{6}{|l|}{ Medical conditions } \\
\hline \multicolumn{6}{|l|}{ Musculoskeletal* } \\
\hline No & $1,348(62)$ & $1,009(55)$ & $551(54)$ & $273(56)$ & $3,181(58)$ \\
\hline Yes & $815(38)$ & $817(45)$ & $474(46)$ & $214(44)$ & $2,320(42)$ \\
\hline \multicolumn{6}{|l|}{ Cancer*** } \\
\hline No & $1,797(90)$ & $1,464(88)$ & $823(89)$ & $395(87)$ & 4,479 (89) \\
\hline Yes & $202(10)$ & $191(12)$ & $103(11)$ & $57(13)$ & $553(11)$ \\
\hline \multicolumn{6}{|l|}{ Cardiovascular* } \\
\hline No & $2,076(88)$ & $1,654(82)$ & $952(82)$ & $446(81)$ & $5,128(84)$ \\
\hline Yes & $286(12)$ & $367(18)$ & $213(18)$ & $106(19)$ & $972(16)$ \\
\hline \multicolumn{6}{|l|}{ Health behaviours } \\
\hline \multicolumn{6}{|l|}{ Smoking* } \\
\hline Nonsmoker & $1,786(84)$ & $1,574(90)$ & $932(94)$ & 447(97) & 4,739 (89) \\
\hline Current smoker & $350(16)$ & $183(10)$ & $59(6)$ & $12(3)$ & $604(11)$ \\
\hline \multicolumn{6}{|l|}{ Alcohol habits* } \\
\hline Abstainer & $853(39)$ & $860(46)$ & $518(49)$ & $253(50)$ & $2,484(44)$ \\
\hline Nonabstainer & $1,353(61)$ & $1,013(54)$ & $538(51)$ & $255(50)$ & $3,159(56)$ \\
\hline \multicolumn{6}{|l|}{ Social support $* * * *$} \\
\hline Yes & $1,808(89)$ & $1,437(89)$ & 791 (87) & $365(88)$ & $4,401(88)$ \\
\hline No & 228 (11) & 187 (11) & $122(13)$ & $51(12)$ & $588(12)$ \\
\hline
\end{tabular}

${ }^{a}$ Respondents only analysed

Significance levels chi-squared overall $P$ values: $* P<0.001$, ** $P=0.202$, *** $P=0.342$, **** $P=0.362$ 


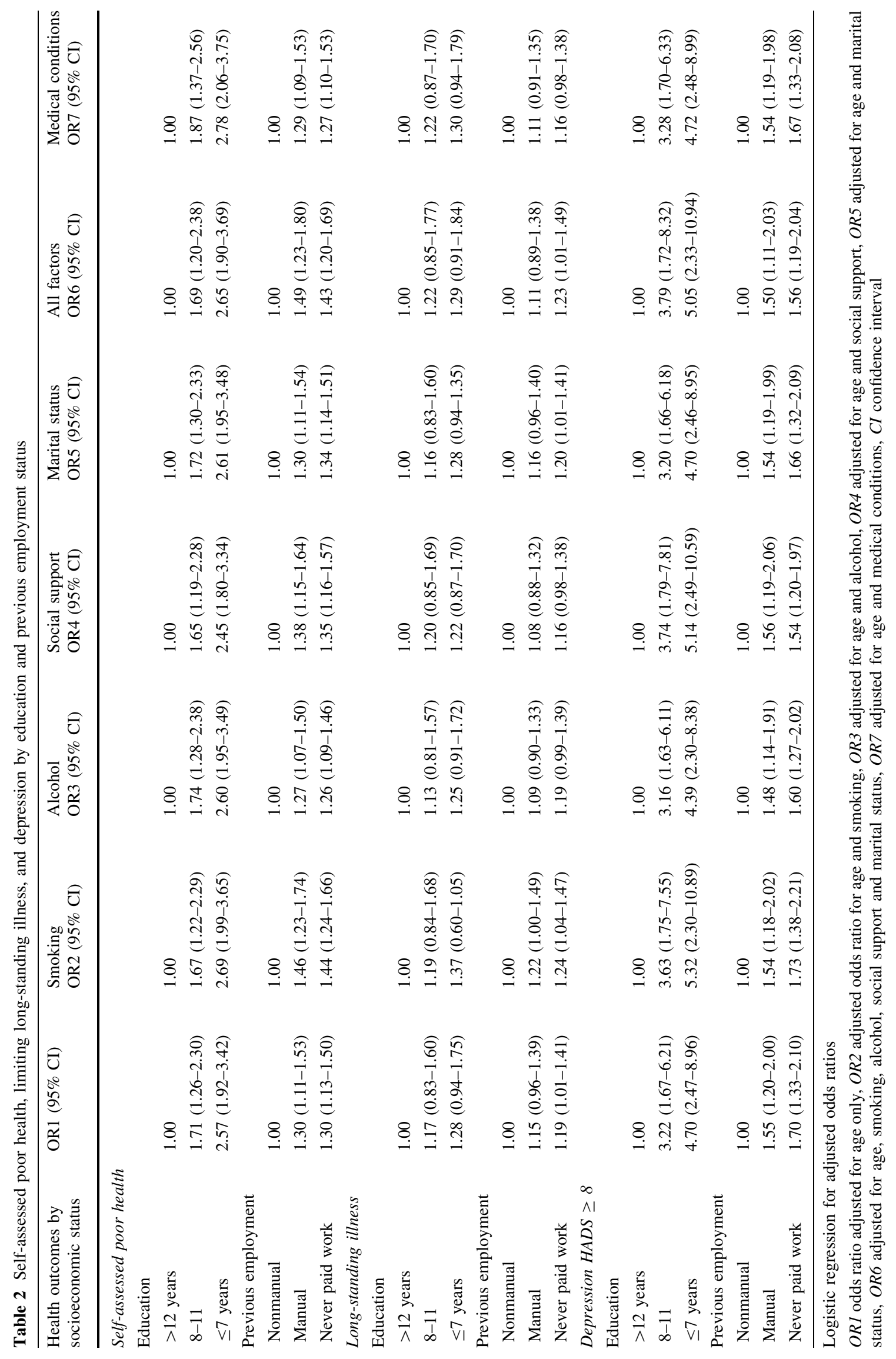


Table 3 Educational and employment inequalities in self-assessed poor health, limiting long-standing illness, and depression

\begin{tabular}{|c|c|c|c|c|c|c|c|c|c|c|c|}
\hline \multirow[t]{3}{*}{ Health indicator } & \multirow{3}{*}{$\begin{array}{l}\text { Age } \\
\text { group }\end{array}$} & \multicolumn{5}{|c|}{ Education in years } & \multicolumn{5}{|l|}{ Employment } \\
\hline & & \multicolumn{3}{|c|}{$\begin{array}{l}\text { Prevalence } \\
\text { rates }(\%)\end{array}$} & \multicolumn{2}{|c|}{ Summary indices } & \multicolumn{3}{|c|}{ Prevalence rates $(\%)$} & \multicolumn{2}{|c|}{ Summary indices } \\
\hline & & $\geq 12$ & $8-11$ & $\leq 7$ & $\begin{array}{l}\text { Rate } \\
\text { difference }\end{array}$ & OR $(95 \% \mathrm{CI})$ & Nonmanual & Manual & Never & $\begin{array}{l}\text { Rate } \\
\text { difference }\end{array}$ & OR $(95 \% \mathrm{CI})$ \\
\hline \multirow{4}{*}{$\begin{array}{l}\text { Self-assessed } \\
\text { poor health }\end{array}$} & $70-74$ & 31 & 42 & 52 & 21 & $2.36(1.54-3.61)$ & 42 & 50 & 53 & 9 & $1.57(1.26-1.95)$ \\
\hline & $75-79$ & 40 & 49 & 58 & 18 & $2.05(1.24-3.39)$ & 52 & 57 & 55 & 3 & $1.14(0.90-1.46)$ \\
\hline & $80-84$ & 31 & 51 & 63 & 32 & $3.79(1.63-8.83)$ & 59 & 59 & 60 & 1 & $1.02(0.73-1.50)$ \\
\hline & $\geq 85$ & 27 & 53 & 64 & 37 & $4.76(1.81-12.52)$ & 49 & 65 & 57 & 6 & $1.37(0.81-2.30)$ \\
\hline \multirow{4}{*}{$\begin{array}{l}\text { Limiting long- } \\
\text { standing illness }\end{array}$} & $70-74$ & 33 & 32 & 35 & 2 & $1.11(0.71-1.74)$ & 32 & 34 & 40 & 8 & $1.42(1.11-1.88)$ \\
\hline & $75-79$ & 33 & 40 & 42 & 9 & $1.50(0.85-2.64)$ & 40 & 42 & 43 & 7 & $1.11(0.84-1.48)$ \\
\hline & $80-84$ & 40 & 49 & 51 & 11 & $1.54(0.62-3.83)$ & 52 & 53 & 50 & -2 & $0.93(0.62-1.40)$ \\
\hline & $\geq 85$ & 50 & 51 & 56 & 6 & $1.27(0.46-3.50)$ & 45 & 65 & 51 & 6 & $1.26(0.70-2.30)$ \\
\hline \multirow{4}{*}{$\begin{array}{l}\text { Depression } \\
\quad \text { HADS } D \geq 8\end{array}$} & $70-74$ & 4 & 15 & 20 & 16 & $5.57(2.02-15.34)$ & 12 & 19 & 19 & 7 & $1.70(1.80-2.40)$ \\
\hline & $75-79$ & 8 & 15 & 21 & 13 & $2.99(1.18-7.58)$ & 13 & 19 & 21 & 8 & $1.71(1.16-2.54)$ \\
\hline & $80-84$ & 5 & 19 & 22 & 15 & $5.87(0.78-44.12)$ & 17 & 17 & 22 & 5 & $1.34(0.78-2.31)$ \\
\hline & $\geq 85$ & 0 & 12 & 21 & 21 & - & 10 & 19 & 19 & 9 & $2.04(0.77-5.41)$ \\
\hline
\end{tabular}

In the age-stratified analyses, the prevalence rates of poor health were clearly higher among the lowest educated in every age group for every health indicator, while the results for employment were less consistent (Table 3). The absolute health inequalities (rate differences) in selfassessed poor health and depression decreased in the age group of 75-79 years, then increased with advancing age, while the results for limiting long-standing illness were nonsignificant. The results for employment showed an inconsistent pattern. The prevalence rates for every health indicator were in general higher with each adverse employment position in every age group, though the oldest never-employed women diverged somewhat from the pattern. The rate differences and the ORs showed an inconsistent fluctuation over the age groups, an initial decrease in self-assessed health and depression was reversed in the oldest age groups, though most differences were not significant. Table 3 indicates that women aged 70-74 years with lowest level of education had an equivalent health evaluation (self-assessed health and depression) to women with 8-11 years of schooling, but $10-15$ years their seniors.

\section{Discussion}

Studying the relation between socioeconomic factors and health in older women aged 70 years and above, we found that SES bore a significant relation to differentials in health. The persisting associations between poor health evaluations and SES could not be accounted for by differences in health behaviour, social support or marital status, neither by differences in prevalence of medical conditions. The association between SES and limiting long-standing illness was not consistent. The educational differences in self-assessed health seemed to increase with advancing age, while the results for long-standing illness and depression and for employment differentials were somewhat inconsistent. Our findings demonstrate that the impact of socioeconomic factors on health were not only strong but enduring. The results do agree with studies showing that socioeconomic inequalities in health endure into old age (Arber and Ginn 1993; Grundy and Holt 2001; Huisman et al. 2003).

The contribution of better educational position to positive health assessment found also in other studies (Grundy and Holt 2001; Huisman et al. 2003) can readily be understood as a higher level of education promoting better paid and more prestigious jobs, allowing more autonomy and control at work, possibly resulting in a raised sense of coping and self-esteem, all of which are factors strongly associated with better health outcomes (Koster et al. 2006). Education used to be strongly socially patterned, and although education represented characteristics acquired in youth, it persisted to relate to health, thus the influences of education seem to be present throughout the life course. Education proved to be a socioeconomic health discriminator opposite to widely held views that education is not considered a good discriminating indicator in older women as most of them left school at obligatory level (Arber and Ginn 1993). The skewed distribution of years of education may have caused a problem in interpretations of results. 
The majority had a low level of education; the large proportion of homogeneously educated might conceal any health inequalities within the group.

Employment status remained a significant predictor of poor health evaluations, a finding agreeing with other research showing that older women in low SES based on previous position in labour market have higher rates of limiting long-standing illness or disability and lower rates of good self-assessed health (Arber and Ginn 1993; Grundy and Holt 2000). In general, women in paid work have better health than those not. Better health of employed women might be a result of the healthy worker effect by excluding the less healthy women from the labour market (Arber 1991). We could not explore whether pre-existing ill-health had accommodated women to domestic work or had prohibited any entrance to the labour market. Nevertheless, previous studies have shown that health advantages of paid work cannot be explained either by the assessments applied or by health-related selection processes (Bartley et al. 1992). We derived women's employment status from their previous position in the labour market, choosing this over the more conventional measure (their husbands' employment) to avoid using different classification for the unmarried. A study examining the classification of elderly women's occupational class according to women's or husband's occupation concluded that it made little difference to the strength of the association between health and occupation, and neither approach had any predominant advantage (Arber and Ginn 1993). The two classifications may differ only for a minor proportion of the women, as most middle-aged women participating in the HUNT survey married quite uniformly into the same occupational group (Rostad et al. 2006). Preretirement employment status was associated with health, but was our classification into three categories too crude to examine the relation? The latter-mentioned study analysing perceived health in middle-aged women, revealed that being employed or not was more strongly associated with health than position in the occupational hierarchy, thus lending support to our conclusion on employment differentials in health in late life (Rostad et al. 2006).

Although health behavioural factors were related to both educational and employment status, they did not explain the differences in health evaluations. It could be that the selected health indicators were inadequate indicators due to low prevalence of smoking and low quantities of alcohol consumption. However, research has shown that life-style does not contribute to the explanation of socioeconomic differences in health among older old (Broese van Groenou 2003; Koster et al. 2006).

Contrary to our expectations, social support did not exert any major influence on the associations between SES and health. Psychosocial factors are claimed to be of particular importance in older women with lower SES, supposedly being more exposed to a variety of risk factors (House et al. 1994). Previous findings have considered the beneficial effect of supportive relations on health by the alleviating of problems of a declining health, in particular mental health, by acting as a stress buffer, and promoting an increased sense of empowerment and control as well as a feeling of coherence (Grundy and Holt 2000; Stevens and van Tilburg 2000). Interestingly, research has shown that perceived social support (as was the case in our study) is more important than the actual assistance provided (Patrick et al. 2001). However, most women, whatever be their SES status, reported adequacy of social support, thus accounting for our results.

Another unexpected result was that marital status did not explain socioeconomic health differentials. However, research has yielded conflicting results on the beneficial marriage effects in older women (Goldman et al. 1995). The absence of institutionalised women may partly explain the result as it has hitherto been assumed that the risk of institutionalisation is related to both health and marital status, and that institutionalised woman are selectively drawn from unmarried groups (Arber and Ginn 1993; Goldman et al. 1995). Other research has claimed that single old women have a lower probability of being disabled than their ever-married counterparts, lending some support to our findings (Goldman et al. 1995). However, the better socioeconomic position of the never-married and their assumed higher risk of institutionalisation may have partly produced the results.

An unanticipated finding was that adjustments for medical conditions did not attenuate the associations between SES and health. Morbidity has been repeatedly shown to effect health evaluations, but morbidity appears not to explain the association between SES and health evaluation. Thus, older women of low SES seemed to have poorer heath evaluations over and above their actual morbidity. To the best of our knowledge, no other study has controlled for medical conditions when analysing socioeconomic differentials in health in older women, thus adding refinement to these associations.

We found that rate differences in self-assessed health among women with lowest and highest educational attainment increased with advancing age (Table 3), thus lending some support to the accumulation theories stating that the effects of disadvantages or advantages add to the effects of one another (Ross and Wu 1996). Nevertheless, the persistence of socioeconomic gradients in the oldest age group was surprising, as we expected that selective survival would tend to eliminate socioeconomic differentials in health. Studies have shown inconsistent results on socioeconomic differences in health with increasing age (Arber and Ginn 1993; Ross and Wu 1996; Huisman et al. 
2003; von dem Knesebeck et al. 2003). Studies are difficult to compare as the socioeconomic factors analysed varies, so do the age groups. Huisman et al. (2003) analysing older women in European countries, using 10-year age bands (60 to $80+$ ), found that educational differences, in terms of rate difference, in self-assessed poor health decreased with age, so did we for women younger than 80 years, but we found education differentials to increase in the oldest age groups. Interestingly, so did Huisman et al. when analysing educational inequalities in older men, the decline was followed by an increase in men aged $80+$. We also showed an increased educational difference in terms of rate difference for depression, adding new knowledge to socioeconomic health differentials in older women. Huisman et al.'s study showed that absolute education differentials in long-term disability in women decreased below the age of 80 years; however, we can make no such conclusion concerning limiting long-standing illness; the differences decreased only in women aged $\geq 85$ years. We considered limiting long-standing illness regardless of the type of illness involved; this nonspecificity may have attenuated the association to SES, since there is evidence that SES gradients are larger in some diseases than others (Broese van Groenou et al. 2003).

To study the elderly is to study survivors, and the older the women the more selected are the survivors in terms of health as well of socioeconomic position. The effect of selection will accumulate as age increases; thus, the health disadvantage of lower educated and manually or never employed women may be underestimated. The mortality selection is an unlikely explanation of health inequalities in the present study.

Several studies have shown that the Norwegian welfare state-despite generous and egalitarian pensions and free access to health services-have not succeeded in eradicating health inequalities in the older (Dahl and Birkelund 1997). Contrary to expectations, comparative studies have found similar health inequalities in Norway than in less wealthy European countries (Mackenbach et al. 1997). Our study expands on these studies.

The present study had several strengths; data were obtained from a large cohort of women, and the participation rate was high. We applied two measures of SES (education and employment, the latter measure not omitting the large proportion of older women never been in paid work as most studies) when examining the relation to three health indicators. We had the unusual advantage of having information on medical conditions, enabling us to assess whether pathology influenced health evaluations. There are also some limitations. First, the surviving women were possibly relatively better educated because of the general excess mortality rates in lower educated women; thus, the estimation of social inequalities in health may be too conservative. Second, although the participation rate was high, the nonrespondents may have had other characteristics than the sample. A study on nonparticipation in the HUNT surveys maintained that nonparticipants did not differ substantially from participants with respect to the factors analysed (Holmen et al. 1990). The participating women's overall response rate to questions, with few exceptions, was very good (80-95\%) and the variations in responses were not systematically related to age. However, participation rate decreased with advancing age (from $80 \%$ among women aged 70-79 years to 53\% among women $\geq 90$ years). Sample-bias may have arisen from the nonparticipation of women residing in the institutions (only 57 women in the sample were institutionalised). Risk of institutionalisation is related both to health and marital status; thus the women without a spouse could be disproportionately represented for good health in the sample, but we find it unlikely that marital selection into institutional care played any significant role. If the proportion of women residing in institutions was greater among women with lower SES, the relative inequalities could be underestimated, but there is no evidence to support that assumption. The effect of excluding institutionalised will expectedly be larger with advancing age, as the proportion of women in institutional care increase with age $(8.0 \%$ of all Norwegian women aged $>67$ in mid-1990s were residing in institutions, rising to $19.8 \%$ of those $>80$ years) (Statistics Norway 2006). It cannot be dismissed totally that nonparticipation of institutional residents has biased the results, thus leading to an underestimation of social differences in health. A third limitation was that information on health came from self-reports, and although self-assessed health status has been shown to correlate well with other health measures, there might have been associations between socioeconomic factors and perceptions of health that might have confounded the results, for example, if lower educated women have systematically lower health expectations than the better educated. As a fourth limitation, information on income or wealth was not available, and economic condition might have led to differences in social circumstances and hence association with health. However, pensions in Norway are universal and quite generous, coupled with mostly free health services; hence, deprived material circumstances were not likely. Several reports show, however, that income is not a good socioeconomic measure for the old and that previous occupational status is more important than current material circumstances, regardless of years since exit from the labour market (Arber and Ginn 1993; Matthews et al. 2005). As a final limitation, the study was limited by its cross-sectional design preventing determination of causal directions. SES was measured at one time point only, and it is possible that associations between accumulated life time 
SES and health evaluations would have been stronger than those shown. A longitudinal study would probably have been more suitable to portray the entire picture of social differentials in health in later life.

Socioeconomic differentials were the key determinant of health inequalities in older women, and the associations remained significant upon adjustments for health behaviour, marital status and medical conditions. Our findings suggest that educational inequalities in health increased with advancing age. Maintaining health in old age, reducing health inequalities, i.e., to avoid those in poorer socioeconomic conditions suffer worse health than those socially better positioned and identifying socioeconomic factors associated with good health in later life, has become a public health issue. Rightly so, current health and welfare policies have a long-term effect on health and any current product of health inequalities might prove difficult to level in the future.

Acknowledgments This study was supported by grants from the Norwegian Women's Public Health Association. The Nord-Trøndelag Health Study (The HUNT Study) is a collaboration between HUNT Research Centre, Faculty of Medicine, Norwegian University of Science and Technology (NTNU Verdal), The Norwegian Institute of Public Health, and Nord-Trøndelag County Council.

\section{References}

Arber S (1990) Revealing women's health: re-analysing the general household survey. In: Roberts H (ed) Women's health counts. Routledge, London, pp 63-93

Arber S (1991) Class, paid employment and family roles. Making sense of structural disadvantage, gender and health status. Soc Sci Med 32(4):425-436

Arber S, Ginn J (1993) Gender and inequalities in health in later life. Soc Sci Med 36(1):33-46

Avlund K, Holstein BE, Osler M, Damsgaard MT, Holm-Pedersen P, Rasmussen NK (2003) Social position and health in older age: the relevance of different indicators of social position. Scand J Public Health 31(2):126-136

Bartley M (2004) Health inequalities-an introduction to theories, concepts and methods. Blackwell, Oxford

Bartley M, Popay J, Plewis I (1992) Domestic conditions, paid employment and women's experience of ill-health. Sociol Health Illn 14(3):313-343

Berkman CS, Gurland BJ (1998) The relationship among income, other socioeconomic indicators, and functional level in older persons. J Aging Health 10(1):81-98

Berkman LF, Glass T (2000) Social integration, social networks, social support, and health. In: Berkman LF, Kawachi I (eds) Social epidemiology. Oxford University Press, Oxford

Bjelland I, Dahl AA, Haug TT, Neckelmann DOG (2002) The validity of the Hospital Anxiety and Depression Scale. An updated literature review. J Psychosom Res 52(2):69-77

Broese van Groenou MI (2003) Unequal chances for reaching 'a good old age'. Socio-economic health differences among older adults from a life course perspective. Tijdschr Gerontol Geriatr 34(5):196-207

Broese van Groenou MI, Deeg DJH, Penninx BW (2003) Income differentials in functional disability in old age: relative risk of onset, recovery, decline, attrition and mortality. Aging Clin Exp Res 15:174-183

Dahl E, Birkelund GE (1997) Health inequalities in later life in a social democratic welfare state. Soc Sci Med 44(6):871-881

Goldman N, Korenman S, Weinstein R (1995) Marital status and health among the elderly. Soc Sci Med 40(12):1717-1730

Grundy E, Holt G (2000) Adult life experiences and health in early old age in Great Britain. Soc Sci Med 51(7):1061-1074

Grundy E, Holt G (2001) The socio-economic status of older adults: how should we measure it in studies of health inequalities? J Epidemiol Commun Health 55(12):895-904

Holmen J, Midthjell K, Bjartveit K, Hjort P, Lund-Larsen P, Moum T, Næss T, Waaler H (1990) The Nord-Trøndelag health survey 1984-1986. Purpose and methods. Report no. 4. National Institute of Public Health, Verdal

House JS, Landis KR, Umberson D (1994) Social relationship and health. In: Conrad P, Kern R (eds) Sociology of health and illness. St Martin's Press, New York, pp 83-92

Huisman M, Kunst AE, Mackenbach JP (2003) Socioeconomic inequalities in morbidity among the elderly; a European overview. Soc Sci Med 57(5):861-873

Joung IM, van de Mheen H, Stronks K, van Poppel FW, Mackenbach JP (1994) Differences in self-reported morbidity by marital status and by living arrangements. Int J Epidemiol 23(1):91-97

Koster A, Bosma H, Broese van Groenou MI, Kempen GI, Penninx BW, van Eijk JT, Deeg DJH (2006) Explanation of socioeconomic differences in changes in physical function in older adults: results from the Longitudinal Aging Study Amsterdam. BMC Public Health 6:244-259

Mackenbach JP, Kunst AE, Cavelaars AEJM, Groenhof F, Geurts JJM (1997) Socioeconomic inequalities in morbidity and mortality in western Europe. Lancet 349:1655-1659

Matthews RJ, Smith LK, Hancock RM, Jagger C, Spiers NA (2005) Socioeconomic factors associated with the onset of disability in older age: a longitudinal study of people aged 75 years and over. Soc Sci Med 61(7):1567-1575

Patrick JH, Cottrell LE, Barnes JF (2001) Gender, emotional support, and well-being among rural elderly. Sex Roles 45:15-29

Ross CE, Wu CL (1996) Education, age and the cumulative advantage in health. J Health Soc Behav 37:104-120

Rostad B, Schei B, Krokstad S (2006) Socioeconomic factors and health in two generations of Norwegian women. Gend Med 3(4):328-340

Statistics Norway (2006) http://www.ssb.no. Statistics Norway, Oslo

Stevens N, van Tilburg T (2000) Stimulating friendship in late life. A strategy for reducing loneliness among older women. Educ Gerontol 26:15-35

von dem Knesebeck O, Luschen G, Cockerham WC, Siegrist J (2003) Socioeconomic status and health among the aged in the United States and Germany: a comparative cross-sectional study. Soc Sci Med 57(9):1643-1652

Waldron I, Hughes ME, Brooks TL (1996) Marriage protection and marriage selection-prospective evidence for reciprocal effects of marital status and health. Soc Sci Med 43(1):113-123

Zigmond AS, Snaith RP (1983) The hospital anxiety and depression scale. Acta Psychiatr Scand 67(6):361-370 